\title{
Three synergistic growth-related mechanisms in the short-term survival of larval Japanese anchovy Engraulis japonicus in Sagami Bay
}

\author{
Akinori Takasuka ${ }^{1,3, *}$, Ichiro Aoki ${ }^{1}$, Isamu Mitani ${ }^{2}$ \\ ${ }^{1}$ Department of Aquatic Bioscience, Graduate School of Agricultural and Life Sciences, The University of Tokyo, 1-1-1 Yayoi, \\ Bunkyo, Tokyo 113-8657, Japan \\ ${ }^{2}$ Kanagawa Prefectural Fisheries Research Institute, Jyogashima, Misaki, Miura, Kanagawa 238-0237, Japan \\ ${ }^{3}$ Present address: National Research Institute of Fisheries Science, Fisheries Research Agency, 2-12-4 Fukuura, Kanazawa, \\ Yokohama, Kanagawa 236-8648, Japan
}

\begin{abstract}
The 'growth-mortality' hypothesis, which holds that larger and/or faster growing individuals will have a higher probability of survival, currently includes 3 functional mechanisms (hypotheses) in its theoretical framework: 'bigger is better', 'stage duration' and the recently proposed 'growth-selective predation', which are based on size, time and per se growth rate, respectively. Through otolith microstructure analysis, we tested these 3 synergistic growth-related mechanisms according to growth characteristics of the survivors vs the original population in the short-term (ca. $2 \mathrm{wk}$ ) survival process of larval Japanese anchovy Engraulis japonicus in the 'shirasu' (larval anchovy) fishing ground in Sagami Bay, Japan. Back-calculated standard length (growth trajectory) and growth rate (growth history) were compared between the survivors (SV) captured on 18 July 2001 and the presumed original population (OP) captured on 1 and 5 July 2001. The larvae from SV were consistently smaller than the larvae from OP until at least the start of the ca. 2 wk survival process (1 July). Daily growth rates, however, were higher for SV than for OP at least at the start of the survival period. Therefore, faster growing individuals survived even if they were smaller than slowergrowing conspecifics. This was probably mediated by predation. Growth histories were generally similar between the metamorphosing larvae and non-metamorphosing larvae older than $40 \mathrm{~d}$, the minimum age for metamorphosis, except for the period immediately after hatching. As such, we failed to detect a clear relationship between growth rates and the timing of metamorphosis (stage duration) as a whole. The results supported and extended the 'growth-selective predation' hypothesis but not the 'bigger is better' hypothesis. The 'stage duration' hypothesis was not unequivocally supported by the present findings.
\end{abstract}

KEY WORDS: Growth rate · Otolith microstructure analysis · Short-term survival · Growth-selective predation hypothesis $\cdot$ Larval Japanese anchovy

\section{INTRODUCTION}

Growth rate during early life history is a determinant of recruitment dynamics of marine and freshwater fish. Simulation and field studies suggest that even subtle variations in growth rate can lead to great fluctuations in population size (Houde 1987, 1989, Campana 1996), and if so, early life growth rates would be a predictor of recruitment success (Houde 1987). A paradigm for larval and juvenile survival processes is summarized in the 'growth-mortality' hypothesis (Anderson 1988), which holds that larger and/or faster growing individuals (or cohorts) will have a higher probability of survival. This scenario has been supported by many field tests (Healey 1982, Post \& Prankevicius 1987, West \& Larkin 1987, Hovenkamp 1992, Campana 1996, Meekan \& Fortier 1996, Hare \& Cowen 1997, Sirois \& Dodson 2000, Searcy \& Sponaugle 2001, Wilson \& Meekan 2002, Allain et al. 
2003, Baumann et al. 2003, Oozeki et al. 2003), laboratory experiments (Rosenberg \& Haugen 1982) and simulation studies (Rice et al. 1993). Anderson (1988) concluded that the 'growth-mortality' hypothesis provides a rational theoretical framework for future studies.

The 'growth-mortality' hypothesis includes several functional mechanisms within its theoretical framework (Hovenkamp 1992, Hare \& Cowen 1997, Searcy \& Sponaugle 2001). The 'bigger is better' and 'stage duration' hypotheses (mechanisms) have explained the relationship between growth and survival according to 2 concepts: size and time (Takasuka et al. 2003). In the 'bigger is better' hypothesis, mortality is assumed to be negatively size-dependent. Larvae with higher growth rates (higher growth larvae) will be larger than those with lower growth rates (lower growth larvae) at the same age, leading to a survival advantage for higher growth larvae (Miller et al. 1988). The 'stage duration' hypothesis, also known as the 'growth-dependent' hypothesis, focuses on the relationship between growth rate and larval stage duration. If growth rates shorten larval stage duration, higher growth larvae should selectively survive, since the probabilities of mortality events will be much decreased (Chambers \& Leggett 1987, Houde 1987). From 2 standpoints, however, these 2 concepts indirectly link growth rate with survival. First, size is just an output of growth rate. Second, the stage duration idea depends solely on the time-integrated cumulative probabilities of lethal events occurring throughout high mortality stages. Moreover, until recently, no direct evidence existed in the field to support the relationship between growth rate and predation mortality, even though predation pressure has been recognized as the primary and direct source of mortality (Bailey \& Houde 1989, Leggett \& DeBlois 1994). Here emerged 2 questions: Is a fish larva with a lower growth rate actually removed by predation at a given moment in the sea? If so, is the mortality size-dependent?

Our previous study (Takasuka et al. 2003) demonstrated direct impacts of growth rates on vulnerability to predation for larval Japanese anchovy Engraulis japonicus through field research. In that study, sympatric larvae and their predatory fish were captured simultaneously by the same tows of a trawler in the 'shirasu' ('larval anchovy' in Japanese) fishing ground in Sagami Bay, Japan. Growth rates, analyzed by otolith microstructure, and larval sizes were compared between the larvae dissected from the stomach contents of their predators (ingested larvae) and the larvae captured simultaneously with the predators (surviving larvae from the original population). The growth rates of the ingested larvae were shown to be significantly lower than those of the surviving larvae, presenting the first snapshot evidence to support the relationship be- tween growth rate and predation mortality in field conditions. The observed selective mortalities were not explained by size-selective mortality. Alternatively, the existence of non-size-related predation mortality was detected by comparing growth rates at the same larval size. Therefore, slower growing individuals were more vulnerable to predation mortality than faster growing conspecifics, even if they were the same size, at a given moment in the sea. This means that growth rates themselves directly affect predation mortality, independently of both negative size-selective mortality and high mortality stage duration. The 'growth-selective predation' hypothesis has been proposed. To date, 3 functional mechanisms - 'bigger is better', 'stage duration' and 'growth-selective predation', based on size, time and per se growth rate, respectively - coexist in the framework of the general 'growth-mortality' theory. These 3 mechanisms are theoretically independent of, and synergistic with, one another.

Earlier studies on the growth-survival relationship have all targeted the time-integrated cumulative mortality, comparing growth features between survivors and the original population (i.e. characteristics of the survivors vs. original population). This is why no direct evidence of a growth-predation relationship had yet been obtained. On the other hand, our previous study included direct examination of the growth rates of the larvae actually ingested by predators. This allowed us to detect 'growth-selective predation'. Conversely, though, 'growth-selective predation' remains to be demonstrated in the time-integrated survival process. If the 'growth-selective predation' mechanism has significant effects on the recruitment dynamics of Japanese anchovy, the mechanism should be detected in the short-term survival process.

In the present study, we tested the 3 synergistic growth-related mechanisms according to characteristics of the survivors vs. original population (i.e. using the traditional method) in a short-term (ca. 2 wk) survival process of larval Japanese anchovy in the shirasu fishing ground in Sagami Bay. First, we investigated the existence of negative size- and growthrate-selective mortalities by comparing the growth trajectories and histories between survivors and the original population in order to test the 'bigger is better' and 'growth-selective predation' hypotheses. Second, the relationship between growth rates and metamorphosis (i.e. larval stage duration) was examined in order to test the 'stage duration' hypothesis.

\section{MATERIALS AND METHODS}

Field sampling. Larval Japanese anchovy were captured by a commercial shirasu trawler in the shirasu 
fishing ground, the same area that we visited in our previous study (Takasuka et al. 2003), near the mouth of the Sagami River in Sagami Bay, Japan (Fig. 1). The first sampling was conducted on 1 and 5 July 2001, and the second was done approximately 2 wk later, on 18 July 2001. Our field samplings were conducted using the methods of the commercial shirasu fishery, which usually targets shoals of Japanese anchovy larvae larger than ca. $13 \mathrm{~mm}$ (standard length, SL) (see 'Discussion'). After sunrise, a net with a cod-end mesh size of $2.3 \mathrm{~mm}$ was towed just above the seabed (ca. 10 $\mathrm{m}$ at deepest), where larval anchovy forage during the daytime (Mitani 1988a). Randomly selected larval anchovy were frozen at $-20^{\circ} \mathrm{C}$ immediately after the trawler landed.

Otolith microstructure measurements. SL of each larva was measured to the nearest $0.1 \mathrm{~mm}$, and then sagittal otoliths were dissected from each individual using a needle. Assuming symmetry of bilateral otoliths (Wang \& Tzeng 1999), the left otolith was fundamentally prepared for growth analysis, although the right one was used if the left one was lost or broken. The otoliths mounted on a glass slide with euparal were observed by a transmitted light microscope with a video camera connected to a computer and monitor. Otolith microstructure measurements were obtained using an otolith measurement system (RATOC System Engineering). In this system, the microscope's field of view is captured on a monitor, allowing a series of otolith microstructure measurements. After a measurement transect was set from the otolith nucleus to the outermost margin, maximum otolith radius (OR) and each daily growth increment width were measured to the nearest $0.1 \mu \mathrm{m}$. According to a previous report, the first growth increment for Japanese anchovy begins at 3 to $4 \mathrm{~d}$ after hatching, when external feeding begins (Tsuji \& Aoyama 1984). Hence, the number of daily growth increments plus 3 was regarded as age in days, hereafter referred to as 'age' alone (Aoki \& Miyashita 2000, Takasuka \& Aoki 2002). Hatching date was determined according to age and date of capture. SL and daily growth rate at each age were back-calculated by the biological intercept method (Campana 1990, Campana \& Jones 1992, Watanabe \& Kuroki 1997, Oozeki \& Watanabe 2000) in order to obtain the growth trajectories and histories of individual larvae. Since the relationship between OR and SL was well expressed as an allometric relationship (data not shown), the back-calculation procedure used an allometric formula that was separately determined for individual larvae, with SL at the first ring deposition fixed at $5.6 \mathrm{~mm}$ (Fukuhara 1983).

Survivors and original population. Hatching date distributions ranged from 15 May to 13 June $(30 \mathrm{~d})$ for the larvae captured on 1 and 5 July $(n=120)$ and from

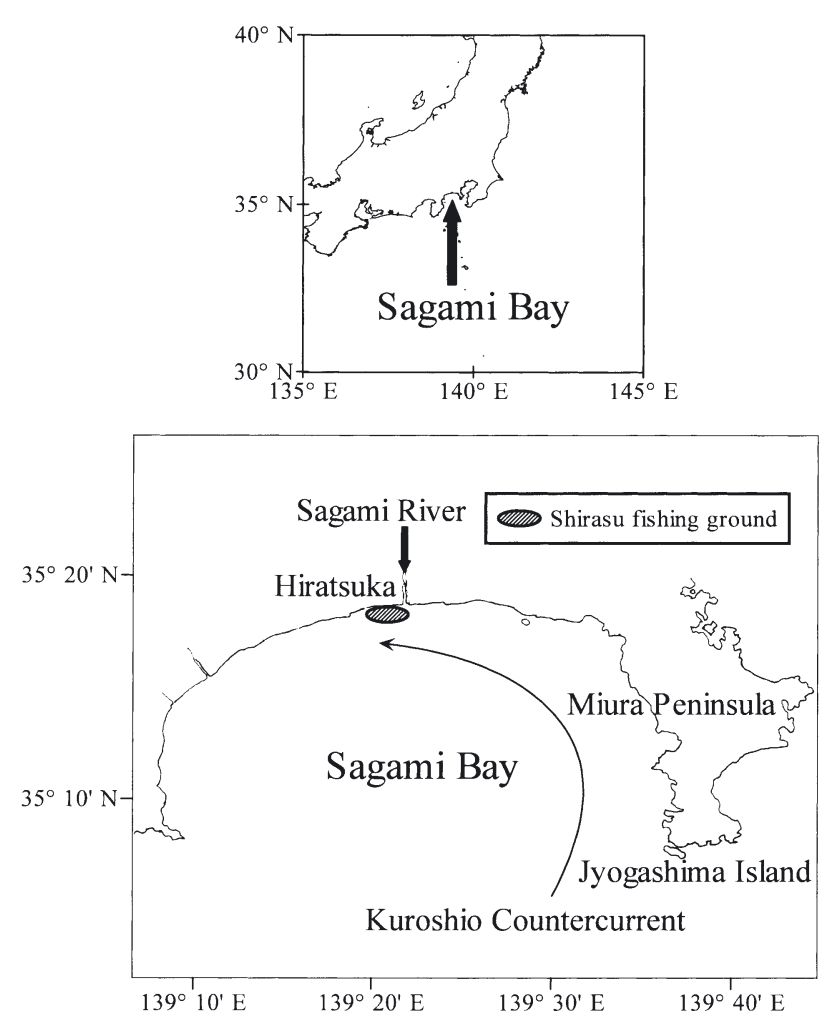

Fig. 1. Shirasu fishing ground near the mouth of Sagami River in Sagami Bay, Japan. Schematic pattern of the current indicated by the curved arrow

30 May to 27 June $(29$ d) for the larvae captured on 18 July $(n=120)$, with the exception of a larva hatching on 26 May (Fig. 2). The overlapping period ranged from 30 May to 13 June (15 d). We assumed that the larval anchovy were retained in the shirasu fishing ground throughout the larval stage after recruitment into the fishing ground (Mitani 1988a, 1990), and thus that the larvae hatching during the same period originated from the same population or cohort regardless of when they were caught, at least during their retention in the fishing ground (see 'Discussion' for details). Accordingly, the larvae hatching from 30 May to 13 June and captured on 18 July $(\mathrm{n}=76)$ were regarded as the individuals surviving ca. 2 wk longer than the larvae hatching during the same period and captured on 1 or 5 July $(n=55)$. The former individuals were designated as the survivors (SV) and the latter as the larvae from the original population (OP). Furthermore, the larvae from SV were divided into 3 subcohorts (SV-I, SV-II and SV-III), each with a 5 d hatching period; likewise, the larvae from $O P$ were divided into 3 sub-cohorts (OP-I, OP-II and OP-III) (Table 1).

Back-calculated growth data can be pooled and rearranged in 2 ways: by calendar date and age. Date-based growth data will better represent tempo- 


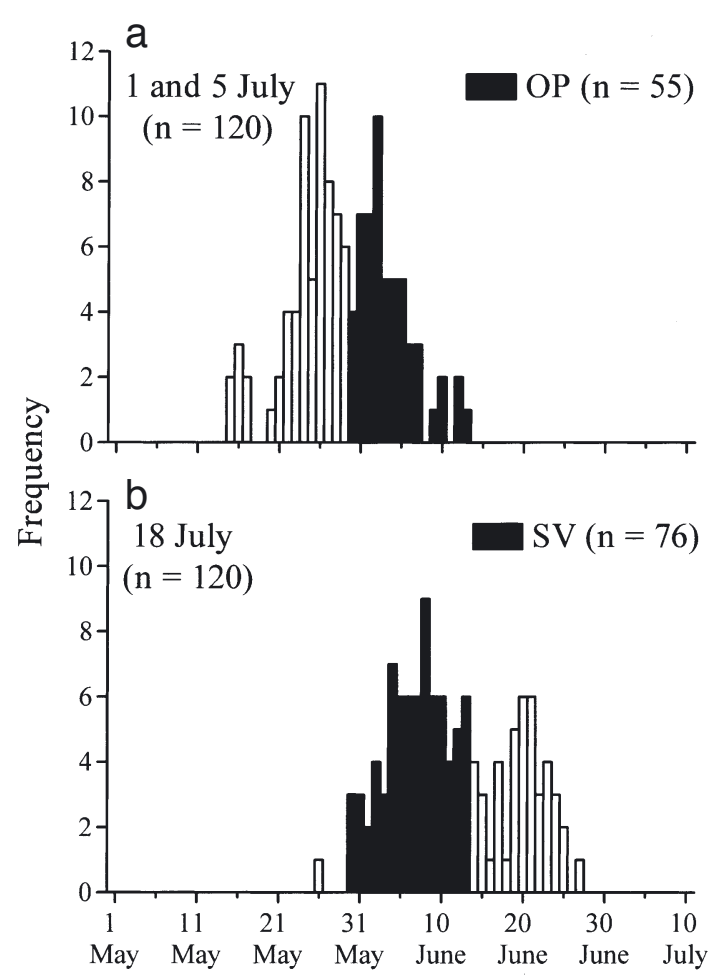

Hatching date

Fig. 2. Engraulis japonicus. Hatching date distributions of the larvae captured on (a) 1 and 5 July and (b) 18 July 2001. Larvae within the common range of hatching dates (30 May to 13 June), which were designated as survivors (SV) or from the original population (OP), are indicated as solid bars. Sample sizes indicated in parentheses

ral changes in growth features with time, while agebased growth data will better match stage-specific changes (Takasuka et al. 2003). Hence we adopted date-based data in order to test the 'bigger is better' and 'growth-selective predation' hypotheses, since we focus on the sizes and growth rates directly prior to the targeted survival period (see below). Daily increment width, back-calculated standard length (growth trajectory) and daily growth rate (growth history), all arranged by calendar date, were compared between $\mathrm{SV}$ and the OP. Assuming predation as the source of mortality (see 'Discussion'), standard lengths and growth rates at each encounter with a predator will directly determine the size- and growth-rate-selective mortalities. Those growth features of the larvae from $\mathrm{OP}$ at a given moment during the targeted survival period (ca. 2 wk) were not directly estimated by the method based on the characteristics of the survivors vs. original population. Accordingly, we focused on the growth features directly before the start of the survival period. However, the previous study detected the 'growth-selective predation' by using mean growth rates from hatching up to capture or predation (Takasuka et al. 2003). Regarding 1 July as the start date of survival, standard lengths on 1 July $\left(\mathrm{SL}_{1}\right.$ July $)$, mean growth rates from hatching up to 1 July $\left(\mathrm{GR}_{\mathrm{m}-1 \text { July }}\right)$, and $3 \mathrm{~d}$ (28 to 30 June) mean increment widths and growth rates before 1 July $\left(\mathrm{IW}_{3 \mathrm{~d}-1 \mathrm{July}}\right.$ and $\mathrm{GR}_{3 \mathrm{~d}-1 \text { July }}$ respectively) were compared between SV and the OP. SL at hatching was fixed at $2.9 \mathrm{~mm}$ (Fukuhara \& Takao 1988), and $\mathrm{GR}_{\mathrm{m}-1 \text { July }}$ was calculated by dividing $\mathrm{SL}_{1}$ July minus 2.9 by daily age on 1 July. All of these parameters were also compared between the corresponding sub-cohorts (SV-I vs. OPI, SV-II vs. OP-II, and SV-III vs. OP-III).

Growth rates and metamorphosis. Guanine was observed on the inside wall of the abdominal cavity in some of the larvae captured on 18 July (see 'Results'). Although the timing of metamorphosis is generally judged

Table 1. Engraulis japonicus. Date of capture, hatching date range, sample size and size and growth data for the larvae as sur-

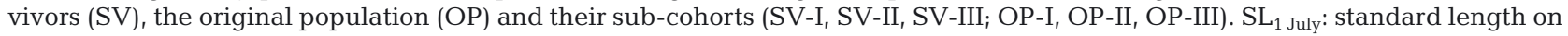
1 July; $\mathrm{GR}_{\mathrm{m}-1 \text { July: }}$ mean growth rate from hatching up to 1 July; $\mathrm{IW}_{3 \mathrm{~d}-1 \text { July }}$ $3 \mathrm{~d}$ mean increment width before 1 July; GR $3 \mathrm{~d}-1$ July: $3 \mathrm{~d}$ mean growth rate before 1 July. + and -: size, growth rate or increment width of SV were significantly larger, higher or wider $(+)$ and smaller, lower or narrower $(-)$ than those of the OP on average ${ }^{*} \mathrm{p}<0.05,{ }^{* *} \mathrm{p}<0.01$ after $t$-tests

\begin{tabular}{|c|c|c|c|c|c|c|c|c|c|}
\hline Sample & $\begin{array}{c}\text { Date of } \\
\text { capture } 2001\end{array}$ & $\begin{array}{l}\text { Hatching } \\
\text { date }\end{array}$ & $\mathrm{n}$ & Age (d) & $\begin{array}{c}\text { SL } \\
(\mathrm{mm})\end{array}$ & $\begin{array}{l}\mathrm{SL}_{1 \text { July }} \\
(\mathrm{mm})\end{array}$ & $\begin{array}{l}\mathrm{GR}_{\mathrm{m}-1 \text { July }} \\
\left(\mathrm{mm} \mathrm{d}^{-1}\right)\end{array}$ & $\begin{array}{c}\text { IW }_{3 d-1 \text { July }} \\
(\mu \mathrm{m})\end{array}$ & $\begin{array}{l}\mathrm{GR}_{3 \mathrm{~d}-1 \text { July }} \\
\left(\mathrm{mm} \mathrm{d}^{-1}\right)\end{array}$ \\
\hline \multicolumn{10}{|l|}{ Cohort } \\
\hline OP & 1 and 5 July & 30 May-13 June & 55 & $22-36$ & $15.6-27.8$ & $21.8 \pm 3.0$ & $0.69 \pm 0.06$ & $6.45 \pm 1.20$ & $0.50 \pm 0.10$ \\
\hline SV & 18 July & 30 May-13 June & 76 & $35-49$ & $21.5-32.4$ & $19.3 \pm 2.3-* *$ & $0.68 \pm 0.05$ & $6.80 \pm 1.21$ & $0.59 \pm 0.11+^{* *}$ \\
\hline \multicolumn{10}{|c|}{ Sub-cohort } \\
\hline OP-I & 1 and 5 July & 30 May-3 June & 33 & $28-36$ & $20.6-27.8$ & $23.2 \pm 2.0$ & $0.68 \pm 0.05$ & $6.49 \pm 1.21$ & $0.47 \pm 0.09$ \\
\hline SV-I & 18 July & 30 May-3 June & 15 & $45-49$ & $26.5-32.4$ & $22.2 \pm 1.5$ & $0.64 \pm 0.04-*$ & $7.13 \pm 1.09$ & $0.49 \pm 0.06$ \\
\hline OP-II & 1 and 5 July & 4-8 June & 16 & $24-31$ & $15.9-26.7$ & $20.9 \pm 2.5$ & $0.70 \pm 0.09$ & $6.67 \pm 1.13$ & $0.54 \pm 0.12$ \\
\hline SV-II & 18 July & 4-8 June & 34 & $40-44$ & $23.8-29.4$ & $19.8 \pm 1.2-^{*}$ & $0.68 \pm 0.05$ & $7.17 \pm 1.19$ & $0.60 \pm 0.09+{ }^{*}$ \\
\hline OP-III & 1 and 5 July & 9-13 June & 6 & $22-26$ & $15.6-20.9$ & $16.6 \pm 2.0$ & $0.68 \pm 0.06$ & $5.62 \pm 1.17$ & $0.56 \pm 0.05$ \\
\hline SV-III & 18 July & 9-13 June & 27 & $35-39$ & $21.5-28.5$ & $17.1 \pm 1.4$ & $0.71 \pm 0.05$ & $6.16 \pm 1.05$ & $0.65 \pm 0.11$ \\
\hline
\end{tabular}


by a meristic character such as the number of fin rays (Youson 1988), Takahashi \& Watanabe (2004a) proposed that presence of guanine on the inside wall of the abdominal cavity or on the surface of the body could be an indicator of the timing of metamorphosis in clupeoid species, on the grounds that the timing of the number of fin rays being constant does not always correspond to that of metamorphosis. In our study, none of the individuals with guanine on the inside wall of the abdominal cavity had morphologically reached the juvenile stage, and so they were determined as the metamorphosing larvae. The youngest metamorphosing larva was $40 \mathrm{~d}$ old (see 'Results'). Therefore, mean growth rates from hatching up to $40 \mathrm{~d}\left(\mathrm{GR}_{\mathrm{m}-40 \mathrm{~d}}\right)$, which were calculated by dividing SL at $40 \mathrm{~d}$, minus 2.9 , by 40 , and daily growth histories from 5 to $40 \mathrm{~d}$ were compared between the metamorphosing larvae and non-metamorphosing larvae older than $40 \mathrm{~d}$. We adopted age-based data in order to test the 'stage duration' hypothesis, since metamorphosis must be a physiological phenomenon, which is closely related to developmental stage.

\section{RESULTS}

\section{Size- and growth-rate-selective mortalities}

Daily increment widths of SV $(n=76)$ were narrower than those of the OP $(n=55)$ for more than $10 d$ around mid-June, although their widths were similar immediately after hatching (Fig. 3). However, daily increment widths of SV became wider rapidly, finally to exceed those of the OP in late June. The $3 \mathrm{~d}$ (28 to 30 June) mean increment widths before 1 July $\left(\mathrm{IW}_{3 \mathrm{~d}-1 \text { July }}\right)$ were $6.80 \pm 1.21$ (mean $\pm \mathrm{SD}) \mu \mathrm{m}$ for $\mathrm{SV}$, which were wider than $6.45 \pm 1.20 \mu \mathrm{m}$ for the OP (Table 1), though the differences were not significant, owing to high variance (Student's $t$-test, $\mathrm{p}=0.101$ ). On the other hand, a comparison of growth trajectories showed that SLs of SV were consistently smaller than those of the OP until at least 1 July. The differences in SLs between SV and the OP averaged ca. 2.5 to $3.0 \mathrm{~mm}$, and SLs on 1 July $\left(\mathrm{SL}_{1 \text { July }}\right.$ ) differed significantly between these 2 groups (Student's $t$-test, $\mathrm{p}<0.001$ ). There were no significant differences in the mean growth rate from hatching up to 1 July $\left(\mathrm{GR}_{\mathrm{m}-1}\right.$ July $)$ between $\mathrm{SV}$ and the OP $(p=0.754)$; however, their growth history patterns differed distinctly. Daily growth rates were lower for SV than for the OP from immediately after hatching up to mid-June, but temporal decreases in growth rates of SV were moderate, while those of the OP were dramatic. Consequently, the daily growth rates of SV were consistently higher than those of the OP after 20 June, when the mean value of daily growth rates of SV exceeded that of the OP. The $3 \mathrm{~d}$ (28 to 30 June) mean growth rates before 1 July $\left(\mathrm{GR}_{3 \mathrm{~d}-1 \mathrm{July}}\right)$ were $0.59 \pm 0.10$ (mean $\pm \mathrm{SD}$ ) $\mathrm{mm} \mathrm{d}^{-1}$ for $\mathrm{SV}$, which were significantly higher than $0.50 \pm 0.10 \mathrm{~mm} \mathrm{~d}^{-1}$ for the OP (Student's $t$ test, $\mathrm{p}<0.001)$.

Comparison of daily increment widths, growth trajectories and histories and related parameters $\left(\mathrm{IW}_{3 \mathrm{~d}-1 \text { July }}, \mathrm{SL}_{1 \text { July }}, \mathrm{GR}_{\mathrm{m}-1 \text { July }}\right.$ and $\mathrm{GR}_{3 \mathrm{~d}-1 \text { July }}$ ) between corresponding sub-cohorts (SV-I vs. OP-I, SV-II vs. OPII and SV-III vs. OP-III) showed trends similar to those of the cohorts overall (SV vs. OP), though the differences between corresponding sub-cohorts were not always significant (Table 1, Fig. 4). Generally, the larvae from sub-cohorts of SV (SV-I, SV-II and SV-III) had smaller sizes $\left(\mathrm{SL}_{1}\right.$ July) but higher-growth rates $\left(G_{3 d-1 ~ J u l y}\right)$ than the larvae from sub-cohorts of the OP (OP-I, OP-II and OP-III) as of 1 July or just prior to it.
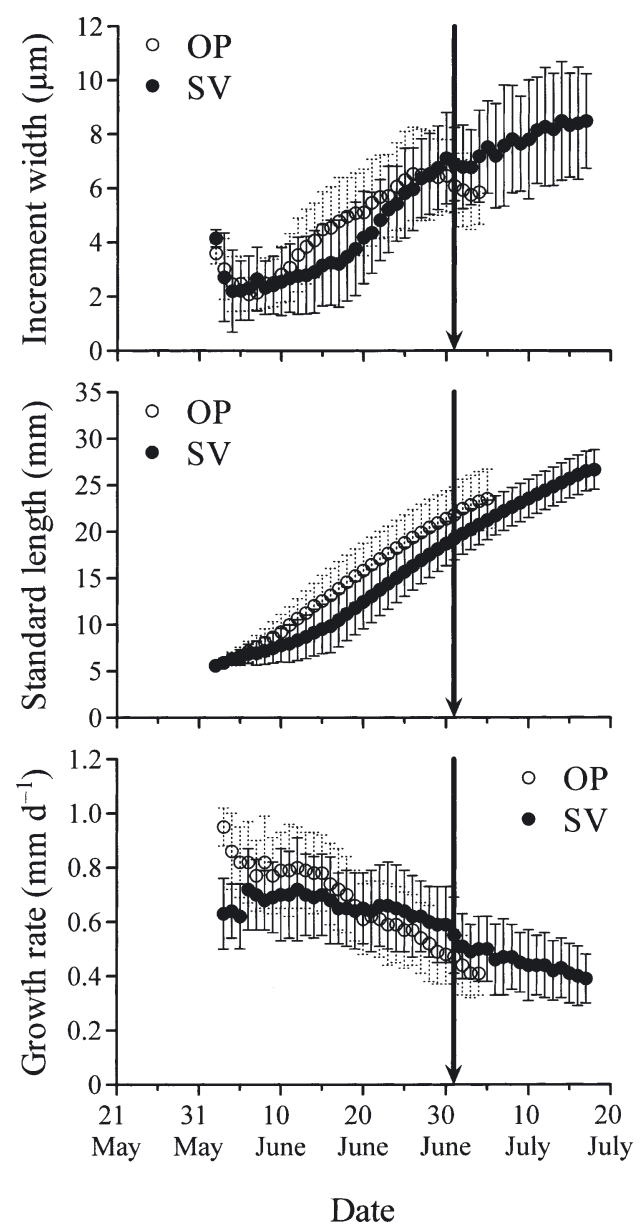

Fig. 3. Engraulis japonicus. Comparison of daily increment width, back-calculated standard length (growth trajectory) and daily growth rate (growth history) between survivors (SV) captured on 18 July 2001 and the original population (OP) captured on 1 and 5 July 2001. Data are pooled by calendar date. Mean \pm SD shown at each date, with at least 3 individual data available. Downward arrows indicate July 1, the start date of the $2 \mathrm{wk}$ survival period 

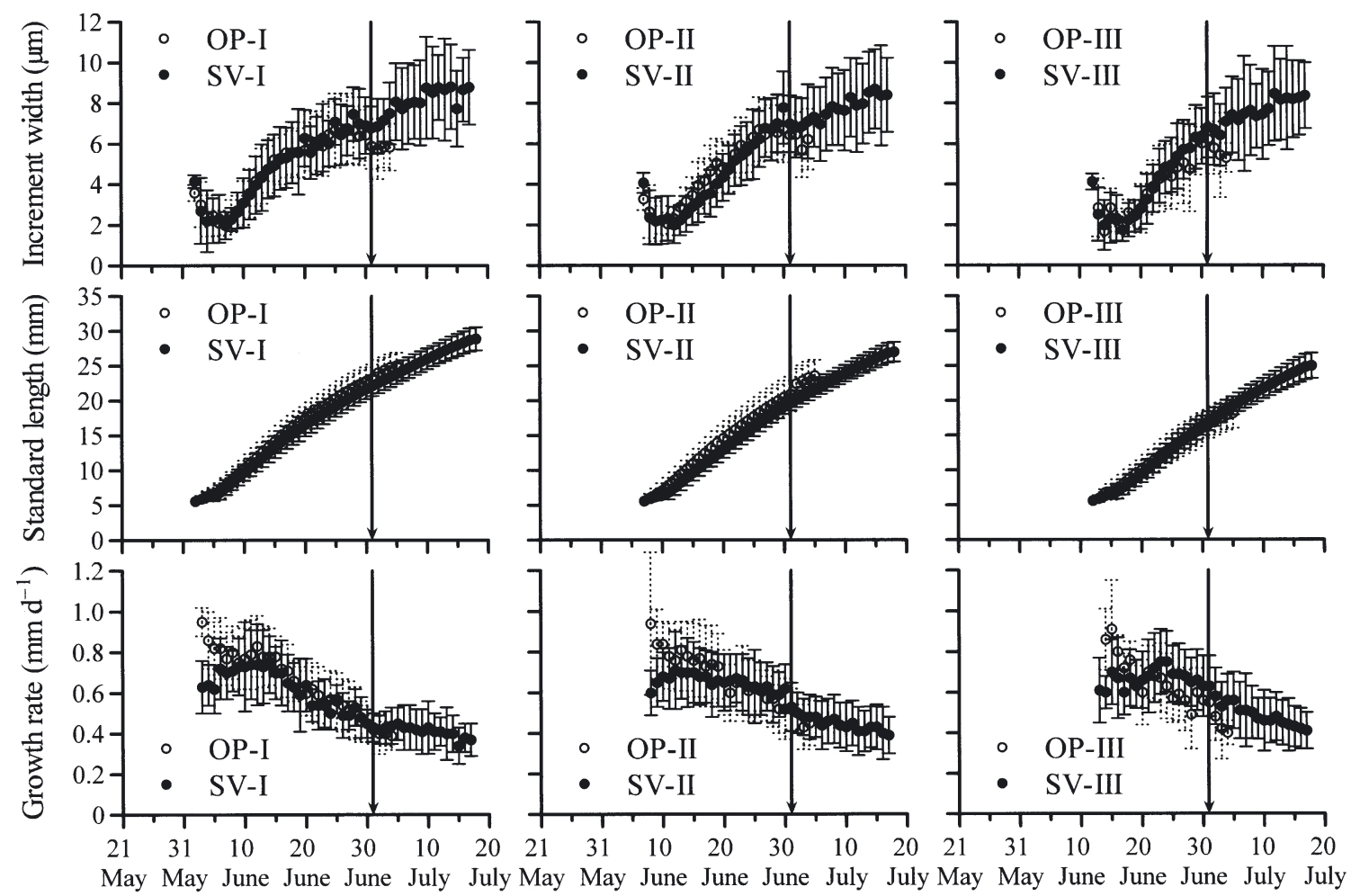

Date

Fig. 4. Engraulis japonicus. Comparison of daily increment width, back-calculated standard length (growth trajectory) and daily growth rate (growth history) between sub-cohorts of survivors (SV-I, SV-II and SV-III) captured on 18 July 2001 and sub-cohorts of the original population (OP-I, OP-II and OP-III) captured on 1 and 5 July 2001. Data are pooled by calendar date. Mean \pm SD shown at each date with at least 3 individual data available. Downward arrows indicate July 1, the start date of the 2 wk survival period

\section{Growth rates and metamorphosis}

Guanine was observed on the inside wall of the abdominal cavity (but not on the surface of the body) in 16 individuals captured on 18 July, which were then determined as the metamorphosing larvae. The minimum size and age of the metamorphosing larvae were $26.4 \mathrm{~mm}$ (SL) and $40 \mathrm{~d}$, respectively, while the maximum size and age of the non-metamorphosing larvae were $30.2 \mathrm{~mm}$ (SL) and $49 \mathrm{~d}$, respectively (Fig. 5).

The growth histories of the metamorphosing larvae, pooled by age, were consistent with those of the nonmetamorphosing larvae up to $40 \mathrm{~d}$, except for the period immediately after hatching (Fig. 6). Comparison of $5 \mathrm{~d}$ mean growth rates (i.e. mean growth rates during 5 to 10,11 to $15, \ldots$ and 36 to $40 \mathrm{~d}$ ) showed no significant differences between the metamorphosing and non-metamorphosing larvae (MANOVA, $\mathrm{p}>0.05$ ), though the former had significantly higher-growth rates than the latter only during 11 to $15 \mathrm{~d}$ ( $\mathrm{p}<0.001$ ). The mean growth rates from hatching up to $40 \mathrm{~d}$ $\left(\mathrm{GR}_{\mathrm{m}-40 \mathrm{~d}}\right)$ were $0.59 \pm 0.03($ mean $\pm \mathrm{SD}) \mathrm{mm} \mathrm{d}^{-1}$ for the metamorphosing larvae $(\mathrm{n}=16)$ and $0.58 \pm 0.04 \mathrm{~mm} \mathrm{~d}^{-1}$ for the non-metamorphosing larvae $(n=34)$. No significant differences were found between these 2 groups (Student's $t$-test, $\mathrm{p}=0.064$ ).

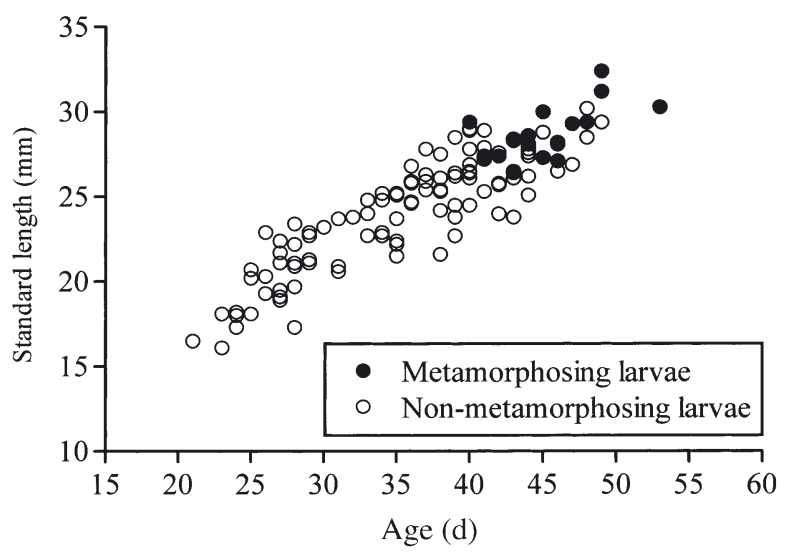

Fig. 5. Engraulis japonicus. Size-at-age data for the metamorphosing larvae $(\mathrm{n}=16)$ and non-metamorphosing larvae ( $\mathrm{n}=104)$ captured on 18 July 2001 


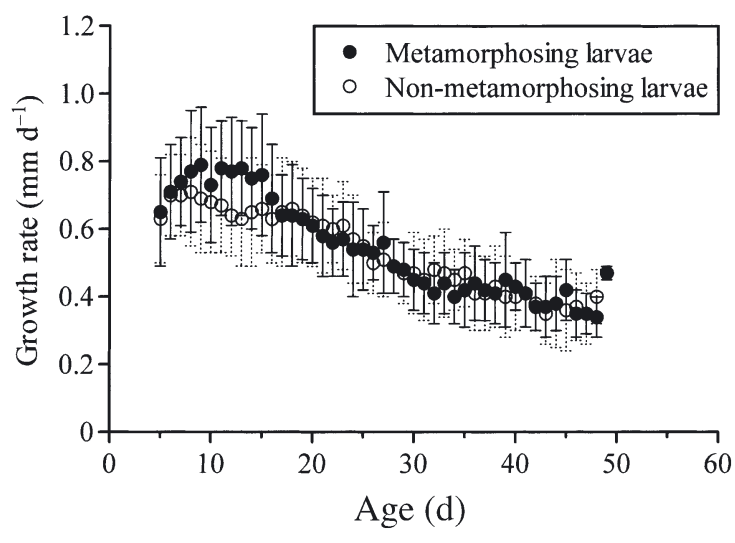

Fig. 6. Engraulis japonicus. Comparison of back-calculated growth histories between the metamorphosing larvae and non-metamorphosing larvae $>40 \mathrm{~d}$ in age and captured on 18 July 2001. Data are pooled by age (ind.). Mean \pm SD shown at each age, with at least 3 individual data available

\section{DISCUSSION}

\section{Survivors vs. original population}

In field tests of the 'growth-mortality' hypothesis, which were based on characteristics of survivors vs. the original population, an assumption that both of them originated from the same population or cohort should be essential (Hovenkamp 1992, Meekan \& Fortier 1996). We assumed that larval anchovy were retained in the shirasu fishing ground and hence that the larvae from SV and the OP originated from the same population or cohort, supported by some lines of circumstantial evidence. Mitani (1990) reported the recruitment process into the shirasu fishing ground for Japanese anchovy during early life history stages. Anchovy females spawn in offshore areas. The eggs are concentrated mainly off Jyogashima Island and are then transported into the bay by the counter-clockwise current (Fig. 1). The larvae entering into the nearshore shirasu fishing ground after crossing the front formed by Sagami River runoff grow to at least $13 \mathrm{~mm}$ (SL), which is considered potentially large enough for active swimming. Larval anchovy have positive taxis toward turbid waters; this is a key factor in the formation of the shirasu fishing ground (Uotani et al. 1994, 2000). Moreover, the larvae are provided with higher prey availability here (Mitani 1988b, 1990). Therefore, we found no reason for positive emigration from such an optimal nursery ground during the larval stage. Also, our assumption seemed to be supported by the hatching date distributions in our 2 samples, which were collected at the ca. 2 wk interval. The hatching date distributions of both samples appeared to be bimodal.
This suggested that each sample would include roughly 2 cohorts, which intermittently recruited into the shirasu fishing ground, probably because of fluctuations in current intensity (Mitani 1988a, 1990). The common range of hatching dates (15 d) between 2 samples corresponded to those of the younger cohort of the sample collected on 1 and 5 July (i.e. the OP) and the older cohort of the sample collected on 18 July (i.e. SV). This, too, would support the assumption that SV was the surviving part of OP.

Previous comparisons between survivors vs. original population have generally targeted the long-term survival processes through either larval or larval and juvenile stages (e.g. Healey 1982, Post \& Prankevicius 1987, Meekan \& Fortier 1996, Good et al. 2001, Takahashi \& Watanabe 2004b). Another focus of previous studies has been the selective survival during horizontal migrations (e.g. Hovenkamp 1992) or settlement with metamorphosis (e.g. Searcy \& Sponaugle 2001). Conversely, we targeted the short-term survival process in the shirasu fishing ground, a relatively closed area. The ranges of hatching date distributions suggested that larval anchovy forage in the shirasu fishing ground for approximately 1 mo. The age of SV and OP ranged from 22 to $36 \mathrm{~d}$ and from 35 to $49 \mathrm{~d}$, respectively. The targeted (2 wk) survival process represents half of the time that the larvae spend in the shirasu fishing ground.

\section{Samples and biases}

Daily growth histories were back-calculated by the biological intercept method, using an allometric formula. We cannot absolutely deny the possibility that this process introduced a bias to the comparison of earlier growth rates between the survivors and the original population, whose ages differed considerably at the time of capture. Previous studies avoided this possibility by using only daily increment widths as an indicator of growth rates (e.g. Thorrold \& Milicich 1990, Searcy \& Sponaugle 2000, 2001, Shima \& Findlay 2002). Comparison of daily increment widths would truly provide the relative merits and demerits of the growth rates of the groups, but not absolute values of those growth rates. Also, if the OR-SL relationship is not linear, the differences in increment widths would not always correspond to those in growth rates between the groups. Accordingly, we used the absolute values of standard lengths and growth rates through back-calculation in order to examine the size- and growth-rate-selective mortalities separately. However, given the possibility of bias as mentioned above, we also used daily increment widths for confirmation. Comparison of daily increment width histories showed that the relative trends between 
SV and the OP were similar to the case in daily growth histories. This supports the results of our comparison of daily growth histories (Fig. 3).

The larvae of various ages, sizes and growth rates are mixed in the natural population in the sea. Nonetheless, experimental studies have often dealt with larvae of the same age or within a narrow age range. In such conditions, variations in growth rates will simply lead to variations in sizes; therefore, the existence of non-size-related mortality will be masked. In other words, the target population or cohort must include the larvae of a wider age range in order to detect the 'growth-selective predation' hypothesis. The present samples (SV and the OP) had an age range of $15 \mathrm{~d}$, which we considered sufficient. However, the frequencies of ages were not uniform $i$ the OP included more of the younger larvae, while SV included more of the older, within each sample (Fig. 2). This could bias a comparison of growth features between SV and the OP. In light of such a viewpoint, we confirmed the results of our overall comparison between SV and the OP (Fig. 3) by comparing SV and the OP at the sub-cohort level, with an age range of $5 \mathrm{~d}$ (Fig. 4). The results at the sub-cohort level were not always sustained by the significance levels owing to rather small sample sizes; however, the similar trends indicated that the lopsided hatching date distributions would not be critical to the date-based comparison of growth features between SV and the OP.

\section{Sources of mortality}

In the traditional approach based on the characteristics of survivors, it is inherently impossible to directly identify the sources of mortality (see 'Introduction'). Without emigration, the possible sources of mortality, other than predation, are starvation and fishing. However, we ignored the possibility of starvation for several reasons. The shirasu fishing ground is an optimal nursery ground by virtue of prey availability (Mitani 1988b, 1990). In fact, feeding incidence calculated as occurrence of feeding individuals surpassed $40 \%$ for the larvae larger than $20 \mathrm{~mm}$ (SL) (Takasuka 2003). Also, starvation mortality is limited to a critical period directly after the start of the external feeding (Hewitt et al. 1985). Feeding failure, if it occurs, could not lead to starvation directly but could affect conditions and growth rates. Larvae with deteriorated conditions and growth rates would be more likely to suffer from predation mortality, owing to lowered potential for anti-predator behaviors (Frank \& Leggett 1982, Yin \& Blaxter 1987, Booman et al. 1991, Mesa et al. 1994, Booth \& Hixon 1999, Chick \& Van Den Avyle 2000, Takasuka et al. 2003). On the other hand, commercial fishing intensity cannot be ignored. A shirasu trawler, however, is quite unlikely to select larval growth rates, since it usually sweeps large shoals of larval anchovy. Even if such a selection were to occur, it would be negligible compared to the selection by predators (Takasuka et al. 2003). In short, we can assume that the shirasu fishery does not impact growth-selective mortality, though it does impact mortality rate itself. From all of the above, the observed selective mortality would be attributed directly to predation. If selective mortality on growth rates is observed, it illustrates the existence of 'growth-selective predation'.

\section{'Bigger is better' and 'growth-selective predation' hypotheses}

The 'growth-mortality' scenario posits that environmental factors affect growth rates, which ultimately determine survival. For larval Japanese anchovy, sea temperature was the principal environmental factor, influencing growth rates positively when it was lower than $21^{\circ} \mathrm{C}$ (Takasuka 2003). Feeding success might also be influential, especially when temperature was higher than $21^{\circ} \mathrm{C}$. From 30 May to $18 \mathrm{July}$, sea surface temperature increased from 18.8 to $25.5^{\circ} \mathrm{C}$, with some fluctuations in Sagami Bay. Thus, variations in both temperature and feeding success would cause the observed substantial variations in growth rates. Such variations in growth rates, and thus sizes, can potentially determine larval survival via the 3 synergistic growth-related mechanisms.

The survivors were consistently smaller than the larvae from the original population until at least the start of the 2 wk survival period, as revealed by a comparison of growth trajectories. This showed that the cumulative size-selective mortality was positively directed such that smaller individuals were more likely to survive. The higher probabilities of mortality among larger individuals have already been reported (Fuiman 1989, Litvak \& Leggett 1992, Pepin et al. 1992, 2003). There are various reasons for positive size-selective mortality. For example, larger body size and the appearance of melanophores may increase conspicuousness (Folkvord \& Hunter 1986, Fuiman 1989). Progress in swimming ability can increase encounter rate with predators (Bailey \& Houde 1989, Cowan \& Houde 1992, Fuiman \& Magurran 1994, Cowan et al. 1996, Paradis et al. 1996). Size-selective mortality is neither universal nor unidirectional (Takasuka et al. 2003): bigger is not always better. The cause of higher mortality of larger larvae cannot be specified in the present study. A simple inference will be that predators would have selected larger larvae to maximize their energy gain (see below). 
On the other hand, the selective mortality on growth rates was directed negatively. Comparison of growth histories showed that the survivors had higher growth rates than the larvae from the original population at least at the start of survival, although the growth histories were somewhat complicated and the survivors had inversely lower growth rates during earlier times. This trend was supported by a comparison of absolute values of daily increment widths. The faster growing individuals at the start of the survival process would have consistently sustained their higher growth rates during the survival period and therefore survived selectively. Here emerged the question of why faster growing larvae survived, while larger larvae did not. Variations in potential for anti-predator behaviors would be the causal background of the 'growth-selective predation' (Takasuka et al. 2003). Slower growing larvae are considered to have lower responsiveness to predator attacks and lower swimming ability, and tend to be isolated from shoals, leading to them being more vulnerable to predation mortality. This would also be true in the case of negative size-selective mortality, since smaller size will also reduce potential for anti-predator behaviors. In this sense, the greater survivorship of faster growing smaller individuals may appear paradoxical at first glance. However, it would be rational from the standpoint of the optimal foraging theory on the side of predators. Size preference by predators will be determined by a trade-off between benefit and cost (Hart 1993, Gerking 1994, Wootton 1998). If predators select larger individuals, they will benefit by obtaining more energy. At the same time, however, the energy cost of pursuing and capturing a larger individual will be greater. Negative selection on prey growth rates will reduce energy loss, since slower growing individuals would be less-capable swimmers and thus easier to catch. Slower growing larger larvae will be preferable to the predators in light of net energy gain.

Another question may be why the survivors had lower-growth rates than the larvae from the original population at earlier stages. Both larvae survived at least until the start date of survival, in spite of their growth differences. The SL of the larvae around 20 June, when the relative merits and demerits of SV and the OP were reversed, roughly corresponded to size at recruitment into the shirasu fishing ground (i.e. ca. $13 \mathrm{~mm}$; see above). In Sagami Bay, the current intensity regulates the recruitment into the shirasu fishing ground (Mitani 1988a, 1990). Thus, we can speculate that the larvae had yet to reach the shirasu fishing ground and had been passively transported by the current for the duration of the lower growth rates of the survivors (i.e. before ca. 20 June). The 'growthselective predation' would become effective with larval development (Takasuka 2003). Therefore, lowered growth rates might not affect vulnerability to predation during the earlier developmental stages.

The results are against the 'bigger is better' hypothesis, but support the 'growth-selective predation' hypothesis. In conclusion, faster growing individuals gained survivorship, even if they were smaller than slower growing conspecifics, and this phenomenon was probably mediated by predation. This may extend the 'growth selective predation' hypothesis that slower growing individuals are more vulnerable to predation than faster growing individuals, even if they are the same size, at a given moment in the sea.

\section{‘Stage duration' hypothesis}

For the 'stage duration' mechanism to come into effect in the regulation of larval survival, 2 essential requirements must be satisfied: (1) high mortality stages must exist for some time period, and (2) growth rates must determine the duration of such stages. In general, the larval stage is a high mortality stage for pelagic fish. In the juvenile stage, the predator field and predation pressure remain unclear, since Japanese anchovy emigrate from the shirasu fishing ground after completing their metamorphosis (Mitani 1988a). However, smaller pelagic predators, such as Japanese jack mackerel Trachurus japonicus and Japanese sardine Sardinops melanostictus, which are the dominant species in Sagami Bay, are expected to be excluded from the predator field of juvenile anchovy (Takasuka 2003). Thus, larvae will suffer higher predation mortality rates than juveniles, and variation in larval stage duration should greatly influence survival.

Fig. 5 suggests that before metamorphosis can begin, the individual could grow to at least $26 \mathrm{~mm}$ (SL) or reach an age of $40 \mathrm{~d}$. Meanwhile, non-metamorphosing larvae of ca. $30 \mathrm{~mm}$ SL or ca. $50 \mathrm{~d}$ old were observed. Assuming a constant duration of metamorphosis, a delay in the start of metamorphosis will equal a delay of the development to the juvenile stage. Assuming that the average age at the start of metamorphosis is $45 \mathrm{~d}$, a variation of $10 \mathrm{~d}$ in the development into the juvenile stage will lead to a variation of more than $20 \%$ in larval stage duration. This would be significant considering the time-integrated cumulative probabilities of mortality.

However, the daily growth rate histories were consistently similar between the metamorphosing larvae and non-metamorphosing larvae, except for the period immediately after hatching (Fig. 6). The growth rates before recruitment into the shirasu fishing ground perhaps affected the timing of metamorphosis; however, we failed to detect a clear relationship between growth rates and the timing of metamorphosis as a whole. The 
results do not deny the theory of the 'stage duration' hypothesis, but they do imply that the growth-survival relationship was not explained by the 'stage duration' concept, at least for the larvae used in this study. We concluded that the larval stage duration per se would influence survival, but that the 'stage duration' mechanism is unlikely to conclusively regulate recruitment dynamics in the shirasu fishing ground.

\section{Growth-related survival mechanisms of pelagic fish}

The present study supported the 'growth-selective predation' hypothesis but not the 'bigger is better' hypothesis. Furthermore, the 'stage duration' hypothesis was not unequivocally supported. However, the relative contributions of these 3 growth-related mechanisms may differ according to taxonomical groups, species, stages and regions. The relationship between growth rates and larval duration (metamorphosis) has been a focus of study especially for a variety of coral reef fishes (Victor 1986, McCormick 1999, Searcy \& Sponaugle 2000, 2001, Victor \& Wellington 2000, McCormick et al. 2002, Shima \& Findlay 2002, Wilson \& Meekan 2002) as well as flatfishes (Chambers \& Leggett 1987, Chambers et al. 1988, Hovenkamp 1992, Bertram et al. 1997). These species are characterized by settlement through metamorphosis. Also, larval duration corresponds to planktonic phase. Therefore, the 'stage duration' mechanism might potentially determine survival. Interestingly, a protracted planktonic larval duration would lead to not only the disadvantages of higher mortality rates, but also the advantages of successful recruitment to a preferable nursery ground, since it can strongly influence the biogeography and community structure of the species via passive transport (Doherty 1991, Victor \& Wellington 2000, Shima \& Findlay 2002).

On the other hand, a protracted larval duration would almost unidirectionally negatively affect the survival of pelagic fish species such as Japanese anchovy. Although metamorphosis generally includes major changes that are morphological (Youson 1988), physiological (Balon 1984) and ecological (Bergman et al. 1988, Thorisson 1994), pelagic fish will undergo gradual rather than sudden changes. Thus, mortality rates and ecological features of pelagic fish can be more continuous through metamorphosis, compared with species that settle through metamorphosis. In addition, pelagic fish generally increase their swimming ability and come to form shoals during the postlarval stage (Matsuura \& Hewitt 1995). Therefore, 'growth-selective predation' would have a more significant role in the recruitment dynamics of pelagic fish species than would the 'stage duration' mechanism.
Such differences in the relative importance of the growth-related mechanisms may reflect differences in the survival strategies.

Acknowledgements. We greatly appreciate the work of Drs. Y. Watanabe, T. Sugimoto (Ocean Research Institute, The University of Tokyo), T. Yamakawa and M. Sano (Graduate School of Agricultural and Life Sciences, The University of Tokyo) for their critical and constructive comments on an earlier draft. We thank C. Fukawa and Y. Fukawa for their support in field sampling with the shirasu fishing boat 'Yoshieimaru'. Also, we express sincere thanks to 4 anonymous referees for their detailed reviews and comments, which clearly polished up our manuscript.

\section{LITERATURE CITED}

Allain G, Petitgas P, Grellier P, Lazure P (2003) The selection process from larval to juvenile stages of anchovy (Engraulis encrasicolus) in the Bay of Biscay investigated by Lagrangian simulations and comparative otolith growth. Fish Oceanogr 12:407-418

Anderson JT (1988) A review of size dependent survival during pre-recruit stages of fishes in relation to recruitment. J Northwest Atl Fish Sci 8:55-66

Aoki I, Miyashita K (2000) Dispersal of larvae and juveniles of Japanese anchovy Engraulis japonicus in the Kuroshio Extension and Kuroshio-Oyashio transition regions, western North Pacific Ocean. Fish Res 49:155-164

Bailey KM, Houde ED (1989) Predation on eggs and larvae of marine fishes and the recruitment problem. Adv Mar Biol 25:1-83

Balon EK (1984) Reflections on some decisive events in the early life of fishes. Trans Am Fish Soc 113:178-185

Baumann H, Pepin P, Davidson FJM, Mowbray F, Schnack D, Dower JF (2003) Reconstruction of environmental histories to investigate patterns of larval radiated shanny (Ulvaria subbifurcata) growth and selective survival in a large bay of Newfoundland. ICES J Mar Sci 60:243-258

Bergman MJN, van der Veer HW, Zijlstra JJ (1988) Plaice nurseries: effects on recruitment. J Fish Biol 33:201-218

Bertram DF, Miller TJ, Leggett WC (1997) Individual variation in growth and development during the early life stages of winter flounder, Pleuronectes americanus. Fish Bull 95:1-10

Booman C, Folkvord A, Hunter JR (1991) Responsiveness of starved northern anchovy Engraulis mordax larvae to predation attacks by adult anchovy. Fish Bull 89:707-711

Booth DJ, Hixon MA (1999) Food ration and condition affect early survival of the coral reef damselfish, Stegastes partitus. Oecologia 121:364-368

Campana SE (1990) How reliable are growth backcalculations based on otoliths? Can J Fish Aquat Sci 47:2219-2227

Campana SE (1996) Year-class strength and growth rate in young Atlantic cod Gadus morhua. Mar Ecol Prog Ser 135:21-26

Campana SE, Jones CM (1992) Analysis of otolith microstructure data. Can Spec Publ Fish Aquat Sci 117:73-100

Chambers RC, Leggett WC (1987) Size and age at metamorphosis in marine fishes: an analysis of laboratory-reared winter flounder (Pseudopleuronectes americanus) with a review of variation in other species. Can J Fish Aquat Sci 44:1936-1947 
Chambers RC, Leggett WC, Brown JA (1988) Variation in and among early life history traits of laboratory-reared winter flounder Pseudopleuronectes americanus. Mar Ecol Prog Ser 47:1-15

Chick JH, Van Den Avyle MJ (2000) Effects of feeding ration on larval swimming speed and responsiveness to predator attacks: implications for cohort survival. Can J Fish Aquat Sci 57:106-115

Cowan JH Jr, Houde ED (1992) Size-dependent predation on marine fish larvae by Ctenophores, Scyphomedusae, and Planktivorous fish. Fish Oceanogr 1:113-126

Cowan JH Jr, Houde ED, Rose KA (1996) Size-dependent vulnerability of marine fish larvae to predation: an individualbased numerical experiment. ICES J Mar Sci 53:23-37

Doherty PJ (1991) Spatial and temporal patterns in recruitment. In: Sale PF (ed) The ecology of fishes on coral reefs. Academic Press, San Diego, p 261-293

Folkvord A, Hunter JR (1986) Size-specific vulnerability of northern anchovy, Engraulis mordax, larvae to predation by fishes. Fish Bull 84:859-869

Frank KT, Leggett WC (1982) Environmental regulation of growth rate, efficiency, and swimming performance in larval capelin (Mallotus villosus), and its application to the match/mismatch hypothesis. Can J Fish Aquat Sci 39:691-699

Fuiman LA (1989) Vulnerability of Atlantic herring larvae to predation by yearling herring. Mar Ecol Prog Ser 51:291-299

Fuiman LA, Magurran AE (1994) Development of predator defences in fishes. Rev Fish Biol Fish 4:145-183

Fukuhara O (1983) Development and growth of laboratory reared Engraulis japonica (Houttuyn) larvae. J Fish Biol 23:641-652

Fukuhara O, Takao K (1988) Growth and larval behaviour of Engraulis japonica in captivity. J Appl Ichthyol 4:158-167

Gerking SD (1994) Feeding ecology of fish. Academic Press, London

Good SP, Dodson JJ, Meekan MG, Ryan DAJ (2001) Annual variation in size-selective mortality of Atlantic salmon (Salmo salar) fry. Can J Fish Aquat Sci 58:1187-1195

Hare JA, Cowen RK (1997) Size, growth, development, and survival of the planktonic larvae of Pomatomus saltatrix (Pisces: Pomatomidae). Ecology 78:2415-2431

Hart PJB (1993) Foraging in teleost fishes. In: Pitcher TJ (ed) Behaviour of teleost fishes. Chapman \& Hall, London, p 253-284

Healey MC (1982) Timing and relative intensity of size-selective mortality of juvenile chum salmon (Oncorhynchus keta) during early sea life. Can J Fish Aquat Sci 39:952-957

Hewitt RP, Theilacker GH, Lo NCH (1985) Causes of mortality in young jack mackerel. Mar Ecol Prog Ser 26:1-10

Houde ED (1987) Fish early life dynamics and recruitment variability. Am Fish Soc Symp 2:17-29

Houde ED (1989) Subtleties and episodes in the early life of fishes. J Fish Biol 35(Suppl A):29-38

Hovenkamp F (1992) Growth-dependent mortality of larval plaice Pleuronectes platessa in the North Sea. Mar Ecol Prog Ser 82:95-101

Leggett WC, DeBlois E (1994) Recruitment in marine fishes: is it regulated by starvation and predation in the egg and larval stages? Neth J Sea Res 32:119-134

Litvak MK, Leggett WC (1992) Age and size-selective predation on larval fishes: the bigger-is-better hypothesis revisited. Mar Ecol Prog Ser 81:13-24

Matsuura Y, Hewitt R (1995) Changes in the spatial patchiness of Pacific mackerel, Scomber japonicus, larvae with increasing age and size. Fish Bull 93:172-178

McCormick MI (1999) Delayed metamorphosis of a tropical reef fish (Acanthurus triostegus): a field experiment. Mar Ecol Prog Ser 176:25-38

McCormick MI, Makey L, Dufour V (2002) Comparative study of metamorphosis in tropical reef fishes. Mar Biol 141:841-853

Meekan MG, Fortier L (1996) Selection for fast growth during the larval life of Atlantic cod Gadus morhua on the Scotian Shelf. Mar Ecol Prog Ser 137:25-37

Mesa MG, Poe TP, Gadomski DM, Petersen JH (1994) Are all prey created equal? A review and synthesis of differential predation on prey in substandard condition. J Fish Biol 45(Suppl A):81-96

Miller TJ, Crowder LB, Rice JA, Marschall EA (1988) Larval size and recruitment mechanisms in fishes: toward a conceptual framework. Can J Fish Aquat Sci 45:1657-1670

Mitani I (1988a) Characteristics of daily age composition of larvae of Japanese anchovy Engraulis japonica in the fishing ground in Sagami Bay. Nippon Suisan Gakkaishi 54:209-214

Mitani I (1988b) Distribution pattern of cyclopoid copepods Oithona spp. in the Shirasu (anchovy larvae) fishing ground in Sagami Bay. Nippon Suisan Gakkaishi 54:215-219

Mitani I (1990) The biological studies on the larvae of Japanese anchovy, Engraulis japonica HOUTTUYN, in Sagami Bay. Spec Rep Kanagawa Prefectural Fish Exper Stn 5:1-140

Oozeki Y, Watanabe Y (2000) Comparison of somatic growth and otolith increment growth in laboratory-reared larvae of Pacific saury, Cololabis saira, under different temperature conditions. Mar Biol 136:349-359

Oozeki Y, Watanabe Y, Kurita Y, Nakata K, Kitagawa D (2003) Growth rate variability of Pacific saury, Cololabis saira, larvae in the Kuroshio waters. Fish Oceanogr 12:419-424

Paradis AR, Pepin P, Brown JA (1996) Vulnerability of fish eggs and larvae to predation: review of the influence of the relative size of prey and predator. Can J Fish Aquat Sci 53:1226-1235

Pepin P, Shears TH, de Lafontaine Y (1992) Significance of body size to the interaction between a larval fish (Mallotus villosus) and a vertebrate predator (Gasterosteus aculeatus). Mar Ecol Prog Ser 81:1-12

Pepin P, Dower JF, Davidson FJM (2003) A spatially explicit study of prey-predator interactions in larval fish: assessing the influence of food and predator abundance on larval growth and survival. Fish Oceanogr 12:19-33

Post JR, Prankevicius AB (1987) Size-selective mortality in young-of-the-year yellow perch (Perca flavescens): evidence from otolith microstructure. Can J Fish Aquat Sci 44:1840-1847

Rice JA, Miller TJ, Rose KA, Crowder LB, Marschall EA, Trebitz AS, DeAngelis DL (1993) Growth rate variation and larval survival: inferences from an individual-based size-dependent predation model. Can J Fish Aquat Sci 50:133-142

Rosenberg AA, Haugen AS (1982) Individual growth and size-selective mortality of larval turbot (Scophthalmus maximus) reared in enclosures. Mar Biol 72:73-77

Searcy SP, Sponaugle S (2000) Variable larval growth in a coral reef fish. Mar Ecol Prog Ser 206:213-226

Searcy SP, Sponaugle S (2001) Selective mortality during the larval-juvenile transition in two coral reef fishes. Ecology 82:2452-2470

Shima JS, Findlay AM (2002) Pelagic larval growth rate 
impacts benthic settlement and survival of a temperate reef fish. Mar Ecol Prog Ser 235:303-309

Sirois P, Dodson JJ (2000) Critical periods and growth-dependent survival of larvae of an estuarine fish, the rainbow smelt Osmerus mordax. Mar Ecol Prog Ser 203:233-245

Takahashi M, Watanabe Y (2004a) Staging larval and early juvenile Japanese anchovy based on the degree of guanine deposition. J Fish Biol 64:262-267

Takahashi M, Watanabe Y (2004b) Growth rate-dependent recruitment of Japanese Engraulis japonicus in the Kuroshio-Oyashio transitional waters. Mar Ecol Prog Ser 266:227-238

Takasuka A (2003) Growth rate and survival mechanism during early life history stages of Japanese anchovy Engraulis japonicus. PhD thesis, University of Tokyo

Takasuka A, Aoki I (2002) Growth rates of larval stage of Japanese anchovy Engraulis japonicus and environmental factors in the Kuroshio Extension and Kuroshio-Oyashio transition regions, western North Pacific Ocean. Fish Sci 68(Suppl I):445-446

Takasuka A, Aoki I, Mitani I (2003) Evidence of growthselective predation on larval Japanese anchovy Engraulis japonicus in Sagami Bay. Mar Ecol Prog Ser 252:223-238

Thorisson K (1994) Is metamorphosis a critical interval in the early life of marine fishes? Environ Biol Fish 40:23-36

Thorrold SR, Milicich MJ (1990) Comparison of larval duration and pre- and post settlement growth in two species of damselfish, Chromis atripectoralis and Pomacentrus coelestis (Pisces: Pomacentridae), from the Great Barrier Reef. Mar Biol 105:375-384

Tsuji S, Aoyama T (1984) Daily growth increments in otoliths of Japanese anchovy larvae Engraulis japonica. Bull Jpn Soc Sci Fish 50:1105-1108

Uotani I, Iwakawa T, Kawaguchi K (1994) Experimental study on the formation mechanisms of Shirasu (Postlarval

Editorial responsibility: Otto Kinne (Editor),

Oldendorf/Luhe, Germany
Japanese Anchovy) fishing grounds with special reference to turbidity. Nippon Suisan Gakkaishi 60:73-78

Uotani I, Fukui A, Kobayashi H, Saito H, Kawaguchi K (2000) The intensity of scattered light in turbid seawater is a major factor in the turbiditaxis of Japanese anchovy larvae. Fish Sci 66:294-298

Victor BC (1986) Duration of the planktonic larval stage of one hundred species of Pacific and Atlantic wrasses (family Labridae). Mar Biol 90:317-326

Victor BC, Wellington GM (2000) Endemism and the pelagic larval duration of reef fishes in the eastern Pacific Ocean. Mar Ecol Prog Ser 205:241-248

Wang YT, Tzeng WN (1999) Differences in growth rates among cohorts of Encrasicholina punctifer and Engraulis japonicus larvae in the coastal waters off Tanshui River Estuary, Taiwan, as indicated by otolith microstructure analysis. J Fish Biol 54:1002-1016

Watanabe Y, Kuroki T (1997) Asymptotic growth trajectories of larval sardine (Sardinops melanostictus) in the coastal waters off western Japan. Mar Biol 127:369-378

West CJ, Larkin PA (1987) Evidence for size-selective mortality of juvenile sockeye salmon (Oncorhynchus nerka) in Babine Lake, British Columbia. Can J Fish Aquat Sci 44:712-721

Wilson DT, Meekan MG (2002) Growth-related advantages for survival to the point of replenishment in the coral reef fish Stegastes partitus (Pomacentridae). Mar Ecol Prog Ser 231:247-260

Wootton RJ (1998) Ecology of teleost fishes. Kluwer Academic Publishers, Dordrecht

Yin MC, Blaxter JHS (1987) Escape speeds of marine fish larvae during early development and starvation. Mar Biol 96:459-468

Youson JH (1988) First metamorphosis. In: Hoar WS, Randall DJ (eds) Fish physiology. Academic Press, San Diego, p 135-196

Submitted: March 20, 2003; Accepted: December 9, 2003 Proofs received from author(s): March 22, 2004 